\title{
Biofuels as an instrument of Russia hydrocarbons and agrarian exports competitiveness
}

\author{
Denis Ushakov ${ }^{1, *}$, Oleg Patlasov ${ }^{2}$ \\ ${ }^{1}$ International college, Suan Sunandha Rajabhat University, 1-U-Thong Nok road, Dusit, 110300, \\ Bangkok, Thailand \\ ${ }^{2}$ K.G. Razumovski Moscow State University of Technologies and Management, 63, Pushkin street, \\ 644010, Omsk, Russia
}

\begin{abstract}
Paper analyzes the prospects of biofuels second and third generation in the structure of the global energy balance, demonstrates a sharp decline in oil and gas revenues in the Russian budget, describes advantages and disadvantages of biodiesel and bioethanol production. The connection between the growth of Russia's export potential in terms of hydrocarbon products processing with EU standards implementation has been proved. The problems of the realization of programs on the oxygenate technologies development in the Union State of Russia-Belarus were revealed. The capacity of the market of 3-4 generations fuel with using non-food raw materials and various types of biomass was estimated. Was proved that at a high level of growth in business value and profitability of production there are incentives to organize deep processing in Russia's hydrocarbon production. It is proved that the oil and gas industry in a creative economy should increase its science intensity and depth of raw materials processing, including ones in related industries.
\end{abstract}

\section{Introduction}

Issues of the pricing system and the formation of a value chains in oil and gas industry, including exploration and development, production and sale typical for oil and gas complex have gained particular importance in the context of the interests disagreement of the Saudis, Russia and the development of shale oil in the United States.

In addition, this aspect is not only associated with the non-conclusion of OPEC + contracts, but also with political factors. The relevance of the topic is also accumulated by the problems of the global transition to a new technological structure - industry 4.0.

Tighter requirements for the environmental characteristics of marine fuels; permissible emissions are regulated by the International Convention for the Prevention of Pollution from Ships (MARPOL). The Convention operates in two directions: it limits the content of

\footnotetext{
*Corresponding author: denis.us@ssru.ac.th
} 
sulfur and nitrogen compounds in fuel. The search for solutions to meet the requirements of the Convention has led to the creation of new marine fuels.

Bioenergy accounts for roughly one-tenth of world total primary energy supply today. Global biofuel production increased 10 billion litres in 2018 to reach a record 154 billion litres. Double the growth of 2017, this $7 \%$ year-on-year increase was the highest in five years. Output is forecast to increase $25 \%$ to 2024, an upwards revision from 2018 owing to better market prospects in Brazil, the United States and especially China [1]. This statistic represents the leading countries in biofuel production in 2018 (Fig. 1).

In related industries, in particular in the electric power industry, a slowdown in the transition to renewable energy is also forecast due to the coronavirus pandemic. As the world faces an unprecedented global health crisis, waves of economic shock have spread in the renewable energy sector, threatening to undermine its progress. According to the International Energy Agency, renewable recourses are a fundamental element of the global economy today, powering almost $30 \%$ of global electricity use. As the world deals with an unprecedented global health crisis, the economic shock waves have rippled through the renewable energy sector, threatening to derail its progress [2].

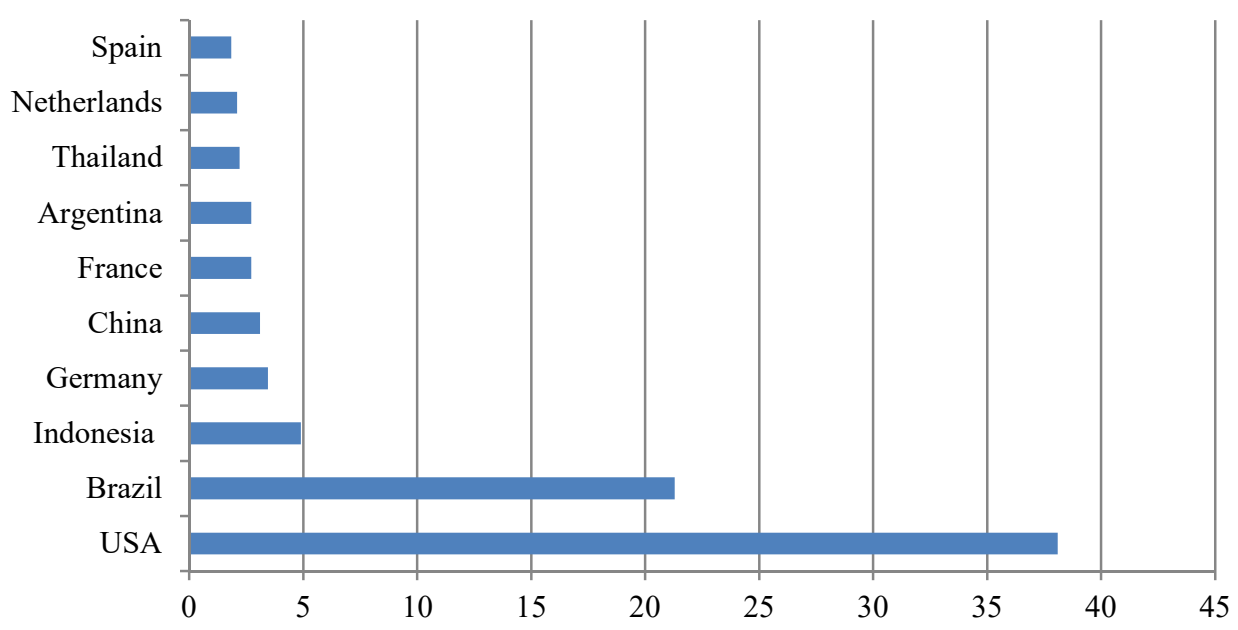

Fig. 1. Leading countries based on biofuel production in 2018 (in thousand metric tons of oil equivalent) [3].

Attempts to create an integrated innovation system for the transition to a low-carbon economy in the context of the Smart Sustainable Districts program (London, Queen Elizabeth Rotterdam Park, Stadshavens Utrecht, Paris Central Station, Doc de San Ken Gothenburg, Johanneberg Copenhagen Moabit West) act for the oil-producing countries only as a backdrop, but in the long term, the share of hydrocarbons in the global energy balance may decrease significantly.

Russian budget revenues in 2019 amounted to 19,9 trillion rubles (18.9\% of GDP), in $2020-20,2$ trillion rubles ( $18.3 \%$ of GDP), in $2021-20,97$ trillion rubles (17.7\% of GDP), including the projected amount of oil and gas revenues in $2019-8,3$ trillion rubles $(7.8 \%$ of GDP), in 2020 - 8 trillion rubles (7.2\% of GDP), and in $2021-8$ trillion. rubles $(6.8 \%$ of GDP) (Fig. 2). The oil and gas revenue contributed approximately 7,9 trillion Russian rubles to Russia federal budget in 2019. In 2018, the figure exceeded 9 trillion Russian rubles, marking a sharp increase compared to the two previous years [4]. 


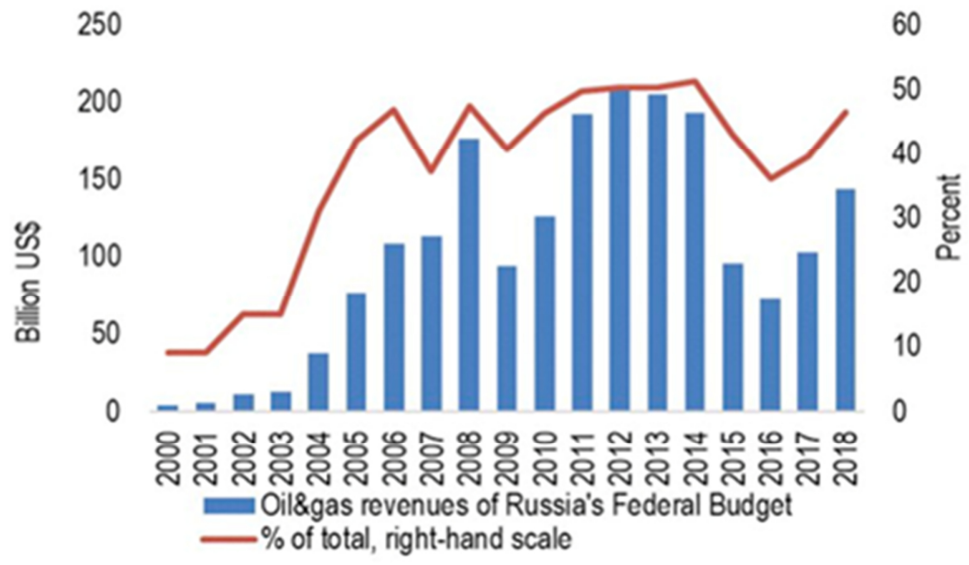

Fig. 2. Oil and gas revenue to the Russian federal budget from 2016 to 2019 (in billion Russian rubles) (Data of Russia Ministry of Agriculture).

\section{Methodology of the study}

Conduction of the study was based on the use of system analysis, systematization, grouping and classification of data, expert assessments methods.

The modern scientific literature does not resolve the question: "How are the network, information, digital, emergent, creative economies located on the scale of post-industrial development?"

Can petrochemistry be considered as a creative industry, and its activity as a creative enterprise?

The authors formulated the following scientific hypotheses to verificate.

1. The oil and gas industry high profitability eliminates the general rule of investment attractiveness growth, depending on the share in the value chain; with a high level of growth in business value and profitability there are no any incentives for deep processing implementation and development.

2. The oil and gas industry in the information economy should increase the science intensity and depth of processing of raw materials, including in related industries.

3. Is the EU Directive on the requirement to add biofuels to hydrocarbon fuels an obstacle to the supply of Russian hydrocarbons with advanced processing into gasoline, kerosene, diesel fuel?

The requirement to add biofuels to traditional fuel is according the EU Directive. For example, in Latvia motor gasoline and diesel fuel should contain 5\% of biofuel, in Finland $15 \%$, Latvia - up to $10 \%$; Estonia, as the only country in the EU that did not require the use of biofuels from suppliers, will also introduce such fuel requirements shortly.

In 2016, the market share of the five largest companies accounted for $22.04 \%$ of global market, which are Renewable Energy, Diester Industries, Neste Oil, ADM and Louis Dreyfus. The global production of biodiesel reached $26567 \mathrm{~K} \mathrm{MT}$. EU is the biggest production base and consumption area of biodiesel, followed by USA, South America and China [5].

According to the estimates of Oil World analysts, biodiesel world production in 2019 is a record 44.8 million tons, which is 3.6 million tons more than the previous year. In particular, it is expected that due to the domestic production state support biodiesel production in Indonesia may increase from 5.4 million tons to 7.4 million tons in a year, 
and in the USA - from 7.2 million tons to 7.6 million tons. In Brazil, biodiesel production in 2020 may reach 5.1 million tons. However, experts note that annual growth may turn out to be lower if the Brazilian government does not increase the share of mandatory biofuels in conventional fuels. At the same time, a decrease in biodiesel production is expected in Argentina - to 2.3 million tons, due to a decrease in demand from the United States [6].

Global "Biodiesel" MarketReport 2020 offers a professional and in-depth study on the current state of the Global Biodiesel Market along with competitive landscape, Biodiesel Market share and revenue forecasts 2026. The global Biodiesel market is valued at 23290 million US\$ in 2020 is expected to reach 25880 million US\$ by the end of 2026, growing at a CAGR of $1.5 \%$ during 2021-2026. [7]

According to Russia Ministry of Agriculture the cultivated areas of rapeseed more than doubled in Russia in 2008-2018 - from 679800 ha to 1576300 ha. The average gross harvest of rapeseed in Russia over ten years amounted to 1.1 million tons, with an average yield of $11.7 \mathrm{~kg} / \mathrm{ha}$. The percentage of yield of such fuel from 1 ton of rapeseed oil is $96 \%$. The increasing popularity of crops is explained by its export increasing [8].

As an alternative fuel biodiesel has the following advantages:

a) it burns with a minimum toxic emissions and carbon dioxide. There are $8-10 \%$ less carbon monoxide, almost $50 \%$ less soot and much less sulfur in the combustion products of biofuels,

b) it has improved lubricating properties compared to mineral diesel;

c) it does not have an unpleasant odor;

d) mixtures of $20 \%$ biodiesel and $80 \%$ diesel fuel are applicable in almost all types of diesel plants (the European designation of the proportion is "B20").

e) $90 \%$ of spilled fuel is decomposed by microorganisms in 3 weeks;

(f) biodiesel production is easy to organize, including on the farms.

g) it is produced from renewable sources - rapeseed, soybean, sunflower, cotton, flaxseed, coconut, corn, mustard, castor, hemp, sesame, peanut, palm and other vegetable oils, as well as animal fats.

Currently, there are several standards for biofuels, for example, biodiesel must comply with ASTM D-6751 (American Society for Testing and Materials) [9]. Standard EN 14214 of the European Committee for Standardization does not allow the production of biodiesel from peanut and palm oil.

Rudolf Diesel (1858-1913), credited with the invention of diesel engine originally used peanut oil as fuel. Over 100 other feedstocks have since been discovered for the production of biodiesel. The choice of feedstock adapted by a country depends on availability, cost and whether it is edible or not. Argentina prefers to use soybean oil contrary to China who has a high demand for soybean for preparation of Chinese food. However edible palm oil is preferred in Asian countries since they have surplus in production while rapeseed oil is preferred in Europe. Other countries such as Ghana are struggling to choose their preferred feedstock since there is not enough of any of the oils whether edible or not [10].

Disadvantages of biodiesel use:

Biofuel combustion products contain only $10 \%$ more nitric oxide compared to petroleum diesel.

This fuel is more aggressive to rubber parts of the engine. At low temperatures, wax crystals form; in the cold season, fuel efficiency decreases. Also, biodiesel can decompose the paintwork of the car.

Biofuel slightly changes the technical and operational parameters of diesel engines: engine power when operating in nominal mode using biofuel is reduced by $6-8 \%$ with an increase in fuel consumption by $5-8 \%$. 
Despite the fact that more than 1 ton of biodiesel can be obtained from a hectare of rapeseed, the crop also involves long periods of crop rotation: the return of rapeseed to the field no earlier than 4 years due to the accumulation of pests and diseases.

Ethanol fuel blends are widely sold in the United States. The most common blend is $10 \%$ ethanol and $90 \%$ petrol (E10). Vehicle engines require no modifications to run on E10 and vehicle warranties are unaffected also. Only flexible fuel vehicles can run on up to $85 \%$ ethanol and $15 \%$ petrol blends (E85) [11].

The main sources of sugar required to produce ethanol come from fuel or energy crops: corn, maize and wheat crops, waste straw, willow and trees, sawdust, reed canary grass, cord grasses, jerusalem artichoke, miscanthus and sorghum plants.

In Europe, wheat is the main crop grown for bioethanol production - accounting for $0.7 \%$ of EU agricultural land and 2\% of Europe's grain supply. The EC has proposed to limit biofuel produced from "food crops" at 7\% of energy use in transport. In Brazil, which has the most mature market for fuel ethanol, the mandatory blend level of anhydrous ethanol was increased to $25 \%$ in May 2013 [12].

In Russia, bioethanol was legally introduced only 2 years ago.

The Federal Law of Russia "On State Regulation of the Production and Turnover of Ethyl Alcohol, Alcohol and Alcohol-Containing Products" defines bioethanol as "denatured ethyl alcohol made from edible and (or) non-edible raw materials of plant origin, the denaturation of which is carried out in compliance with the requirements established by the law on state regulation of ethyl alcohol, and containing not more than $1 \%$ water".

\section{Results of the study}

Conducted research and implementation of the project of the Union State of Russia Belarus allows us to obtain the following results:

1. The role of small business and startups in the oil and gas industry: small-tonnage production carries more risks, including criminal ones. An example is the fraudulent scheme of the Krutogorsky Oil Refinery (Omsk Region), which is caught with low-quality diesel fuel selling, fraud with cheaper heating oil under the guise of diesel fuel, and nonpayment of excise taxes; in 2019 a bankrupt oil refinery was sold for half a billion rubles. Typical fraudulent schemes: fake contracts with offshore companies aimed at artificially creating payables in order to control bankruptcy proceedings. A similar situation is not possible with large companies such as, for example, GAZPROMNEFT-ONPZ JSC located in the region. Small business can exist exclusively in certain niches in the field of waste management, packaging, etc.

2. There is no technical and economic need for the development of biofuel production in Russia; the need is determined only for realizing the export potential. It should not be discounted that the position of the FAO is disapproving of the production of first-generation biofuels - from food ingredients, when part of the world's population is starving. About 113 million people in 53 countries experienced severe food shortages in 2018, according to a report by the European Union, the Food and Agriculture Organization of the United Nations (FAO) and the World Food Program (WFP). In addition, another 143 million people in another 42 countries are just one step away from acute hunger. [13]

The majority of people faced with severe food shortages - almost two-thirds - live in eight countries: Afghanistan, the Democratic Republic of the Congo, Ethiopia, Nigeria, South Sudan, Sudan, Syria and Yemen [14].

The Russia-Belarus Union State programs funded the Research and Development of High-Performance Information and Computing Technologies programs to increase and efficiently use the resource potential of the Union State hydrocarbon resources (SKIF- 
NEDRA 2015-2018) and Innovative Development of Potato Production and Jerusalem artichoke for 2013-2016. The project for the production of oxygenates (bioethanol and butanol) and dry forage from Jerusalem artichoke as part of the Program was implemented on the basis of OJSC "Urzhumsky Distillery". 37 million rubles were allocated for the development and creation of experimental equipment for the production of oxygenates (bioethanol) and dry feed. Budget financing, extrabudgetary funding amounted to 36 million rubles.

\section{Conclusions}

Stable record grain crops in Russia of 120-140 million tons allow, in principle, about 10 million tons of grain to be sent for bioethanol processing with the subsequent transfer to refineries for the production of more environmentally friendly motor fuels for the exporting purpose. In Russia, raw materials and capacities are sufficient for bioethanol production but the minimum capacity of the domestic market and export potential is limited.

Since the debate about the ratio of food and fuel is growing, the use of non-food raw materials and biomass types will be a promising direction, in our opinion. Technologies for the development of second-generation biofuels, which are made from wood, plants and waste, are being improved. According to experts of the German company Choren Industries $\mathrm{GmbH}$, the fastest growing willow is the most energy-intensive plants for secondgeneration biofuels in Europe, and eucalyptus in subtropical and tropical zones.

Biobutanol has advantages over bioethanol in terms of the possibility of a higher level of addition to hydrocarbon fuels without modernizing engines, the inability to use it in any form as an alcoholic beverage, but the production costs are quite high.

Biofuels of third (algae as a source) and fourth generations (the biofuel class includes electrofuels and photobiological solar fuels) in the near future will not be able to have a significant share of the biofuel market.

The significant development of small business in the oil and gas industry is an erroneous line of business. Realization of the unused potential of industrial small business in oil refining and petrochemicals is possible in strictly defined niches such as recycling old tires by pyrolysis with low power equipment, creating sulfur concrete production by utilizing sulfur by-product, packing automobile oils in cans, and manufacturing motor oil additives.

There is a "gap" of entrepreneurs specializing in the construction and commissioning of production within the framework of public-private partnerships or state subsidies and operators, when the functioning of real production is unprofitable.

\section{References}

1. Biofuel production forecast to increase $25 \%$ over the next 5 years (2018) https://www.iea.org/fuels-and-technologies/bioenergy

2. H. Bahar, Renewable Energy Markets and Policy Commentary. The coronavirus pandemic could derail renewable energy's progress. Governments can help (2020) https://www.iea.org/commentaries/the-coronavirus-pandemic-could-derail-renewableenergy-s-progress-governments-can-help

3. T. Wang, Global biofuel production by select country 2018 (2019) https://www.statista.com/statistics/274168/biofuel-production-in-leading-countries-inoil-equivalent/ 
4. Statistic Research Department, Russian federal budget oil and gas revenue 2016-2019 (2020)

5. Biodiesel Market (2020) https://www.marketwatch.com/press-release/biodieselmarket-2020-top-countries-data-global-analysis-size-growth-defination-opportunitiesand-forecast-to-2026-2020-02-05

6. Biodisel world production seeks to record (2019) https://oilcapital.ru/news/markets/2805-2019/k-rekordu-stremitsya-mirovoe-proizvodstvo-biodizelya

7. Global Biodiesel Market Research Report https://www.360researchreports.com/global-biodiesel-market-15055883

8. Over 10 years, the cultivated area of rapeseed in Russia has more than doubled (2019)

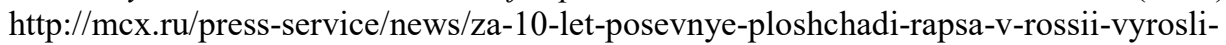
bolee-chem-v-dva-raza/

9. Annual Book of ASTM Standards (2008)

10. G.K. Ayetor, A. Sunnu, Alexandria Engineering J. 54(4), 1285-1290 (2019)

11. A. Př́vara, Transnational Marketing Journal 7(1), 59 - 72 (2019)

12. I. Onyusheva et al., Inter. J. of Energy Economics and Policy 8(2), 148-153 (2018)

13. O. Sivash et al., Inter. J. of Ecology and Development, 32(4), 169-182 (2017)

14. V. Samarina et al., Inter. J. of Energy Economics and Policy 8(2), 140-147 (2018) 